Roy, J., \& Lecea, A. D. (2014). The TTIP: The Transatlantic Trade and Investment Partnership between the European Union and the United States. Miami: Jean Monnet Chair, University of Miami.

First of all I think I should apologize, since any article written prestigious Law Journals like this one, are usually subjects of rabid news, treated extensively in different media such as economy newspapers, radio, television, etc. or other mass media.

This case is an exception to this general rule, since I am going to analyze an issue, which is still extremely topical, but hardly mentioned in the mainstream media. Trade agreements reached by the European Union within the framework of its commercial relationships with other international agents and their economic, political, social, environmental and other implications of this nature.

This analysis of EU trade policy is structured in three broad areas, based on the "TTIP. Transatlantic Trade and Investment Association" division made by Joaquín Roy and Roberto Domínguez.

First, a comprehensive study of the treaty, carried out through a study and evaluation of the origins, main motivations, prospects and foreseeable consequences of the possible entry into force of the TTIP, as well as the main obstacles it faces the negotiation of the agreement in addition to putting it in relation to other similar agreements such as CETA, MERCOSUR, etc.

Secondly, a presentation of the challenges we face, financial, economic, political, social, environmental...etc. and the implications of these agreements have on them.

Finally, a section of conclusions gathering the main ideas presented throughout this study.

\title{
I. EU Trade Policy
}

TTIP, CETA, MERCOSUR, “EU and Japan's Economic Partnership Agreement"

The study of Joaquín Roy and Roberto Dominguez proposes an analysis of the economic relations between the United States and the European Union under the light of 
the negotiations which aim at the establishment of a Transatlantic Partnership of Commerce and Investment.

During the last two hundred years, the international economy has been dominated by the North Atlantic countries, firstly by Western Europe, alone, and later by Europe and the United States, with a clear leadership of the latter since the conclusion of the Second World War.

However, in the coming years it is foreseeable that the loss of the relative weight of the North Atlantic axis will be consolidated in the international economy - which began to be felt for two decades and accelerated with the Great Recession - in favor of emerging countries, especially those in Asia.

In light of this scenario, to which it should be added that the transatlantic economies are heavily indebted and afflicted by lean economic growth, the United States and the countries of the European Union have begun negotiations to form a Transatlantic Association for Trade and Investment (TTIP), which would constitute the largest and deepest free trade area in the world, with a coverage of almost 50\% of world GDP, 30\% of global merchandise trade, $40 \%$ of of services and $20 \%$ of foreign direct investment (FDI) flows.

Negotiations began in 2013 to facilitate exchanges between two regions totaling $60 \%$ of world GDP, but also with a more ambitious goal: to harmonize regulations and thereby set standards for the rest of the world.

While the authorities of the United States (Obama Administration) and the European Union have emphasized the enormous economic benefits that TTIP would generate from being negotiated successfully, we assume that the agreement is not exempt from an underlying geopolitical purpose.

On the one hand, it seeks to revitalize the transatlantic relationship to face the trend that in the near future the most dynamic economic growth will be consolidated in the Pacific basin, nourishing the potential for Asian economies to impose their dominance; on the other hand, it seeks to recover for the United States and the European Union the power to establish the basic rules of the international economy that they enjoyed after World War II. (Bretton Woods Agreements) 
These aspirations will not be easy to achieve. In the first place it will be necessary for the United States and the European Union to agree on the new trade rules, which will be very complex in light of the different regulatory traditions on each side of the Atlantic.

Secondly, even if the negotiations were successful, there is no certainty that emerging countries will comply with the new agreed rules. Otherwise, the international economy could fragment into antagonistic regional integration processes, which would imply a severe blow to the already weakened World Trade Organization (WTO) .

Trade and investment relations between the United States and the European Union

The United States and the European Union have an essential role in the world trading system. The United States contributes $8.3 \%$ of total exports of goods in the world and $12.3 \%$ of imports. Similarly, its share in world service exports is $13.9 \%$ of the total, while importing $9.4 \%$ of the total. On the other hand, exports of goods from the European Union to the world are equivalent to $15.3 \%$ of the total, while their imports are $14.7 \%$ of the world total. With regard to trade in services, the European Union contributes $25.1 \%$ of world exports and $19.7 \%$ of imports.

In terms of exports, the main trading partners of the European Union are, in order of importance, the United States (18.3\% of the total), China (9.7\%), Switzerland (8.2\%), Russia (6.1\%) and Turkey (4.4\%). Regarding imports, its main partners are China (17.9\% of the total), United States (12.2\%), Russia (10.8\%), Switzerland (5.7\%) and Norway $(5.2 \%)$.

The main destinations for exports from the United States are, in order of magnitude, Canada (19.2\% of the total), the European Union (17\%), Mexico (14.8\%), China (7.6\%) and Japan (4.1\%). Similarly, the main points originating from its imports are China (19.9\% of the total), the European Union (17.8\%), Canada (14.8\%), Mexico (12.5\%) and Japan $(5.7 \%)$.

Thus, we find that the United States and the European Union are mutually relevant. For the first, the European Union is the second main destination of its exports and the second origin of the most important goods. In parallel, the United States is the main export destination of the European Union and the third country in which goods are most imported. 
It is a fact that despite the enormous dynamism and growth that the Asian and emerging economies have achieved in recent years, the United States and the European Union are still two relevant players in the international economy, while maintaining an open, fluid bilateral economic relationship, vigorous, with great potential for expansion and with a transcendental importance for the world economy.

\section{CETA, TTIP, MERCOSUR}

Although the long shadow of economic protectionism, amplified by populism is growing all over the world (America First and other protectionist rhetoric ) relatively recently it was possible to ratify the free trade agreement between the EU and Canada, an agreement that will have an impact of 12,000 million euros for the EU, and of 8,000 million for the North American country and will increase the exchanges between the two areas around 20 or $25 \%$.

CETA shares with the TTIP, the fact of being an ambitious agreement since it not only provides for the elimination of tariffs on most products, but also a substantial improvement in the conditions of access to services markets and public procurement. It also includes very important chapters related to the protection of intellectual property, trade facilitation, temporary worker movement, homologation of titles etc.

Responding to the criticisms that these agreements raise in some social agents, who argue that they harm the small business owner and benefit only the large corporations. It is worth mentioning that it is these large companies that have the resources and capabilities necessary to adapt to different regulatory environments. However, many SMEs often give up exporting or implanting in a country because the costs required for adaptation to a regulatory framework are too high.

In this line, are the other free trade mentioned above such as MERCOSUR or the agreement with Japan.

Agreements that not only seek to eliminate bureaucratic and tariff barriers, but also to create free trade zones in an increasingly globalized and regionalized world. 


\section{Implications}

These regulations will be of great importance not only to the United States and the European Union, but also to the rest of the world. Given that it is estimated that the TTIP will become a new standard for the negotiation of trade agreements in the $21 \mathrm{st}$ century, its requirements will be crucial for the evolution of the multilateral trading system.

\section{The TTIP in response to changes in economic power worldwide}

Since the 1980s, when the process of globalization of the international economy accelerated, the focal point of global economic dynamism has slowly moved from the Atlantic to the Pacific. At first these changes did not impose a challenge to the leadership - economic, political and cultural - of the Atlantic economies. Emerging economies simply had to adopt the rules imposed by Western countries.

However, with the explosion of the international financial crisis of 2008, and the Great Recession that prompted, the process of convergence between the main emerging economies - especially in Asia - and the advanced economies of the West has accelerated. While the former were little affected by the crisis, and in fact quickly surpassed it, the latter have been permeated by vicious circles of low economic growth and high indebtedness that has prevented them - especially in the eurozone - to recover the leadership they had in last.

The growing importance of developing countries in the global economic field is undeniable from every perspective.

According to the International Monetary Fund (IMF), the participation of emerging countries in the world economy has increased from $42.6 \%$ in 2000 to $57 \%$ in 2018 ;

The same institution foresees that by next year such participation will be $60 \%$.

In a related way, the participation of the United States and the European Union in the world economy has deteriorated and it is expected that it will continue doing so in the future. 
Given the above, as well as the fact that in recent years clear questions have been expressed about the economic models of the United States and the European Union and their leadership - we consider that the TTIP can be perceived as a reaction from the United States and the European Union to its relative decline, and as an instrument to regain its prominence in international economic affairs.

The purpose of the United States and the European Union is to revitalize its power indirectly - that is, without causing a conflict with emerging economies - by creating new rules in the international economic sphere. Similar to what they did when creating the GATT, the goal is to redefine the international economic structure based on guidelines that reflect their values, preferences and interests.

\section{Conclusions}

The TTIP originated from the search of the United States and the European Union to maintain, and even expand, its power in the international economic system, especially in light of the changes that result from the rise of new emerging powers, such as China and India, to name a few.

The changes in the structure of world production have led the last administrations of the United States government to propose a strategy that allows it to continue determining the rules that regulate the main commercial flows in the coming decades, although it seems that the latter, the Trump administration is determined not to see it, and to go against the sign of the times, turning former allies and political and commercial partners into enemies, and making protectionism and unilateralism a flag

We have all been witnesses, of how actions such as the withdrawal of agreements as relevant as the TPP or the Paris climate agreement, are benefiting notably the natural adversary of political and economic liberalism, China, giving it a leadership which has allowed him to become second global power and discussing the first position, breaking American hegemony, after the fall of the Berlin wall.

And this is where the EU comes in, reinvindicating itself as an actor with global influence, an actor capable of combining economic freedom but also political and democracy, as an inseparable union as an antidote to Chinese authoritarianism. 
The consummation of the TTIP will affect not only economic exchanges between the parties involved, but also those of the United States and the European Union with the rest of its business partners. The TTIP also has the capacity to put an end to the lethargy that has permeated the multilateral trading system as a result of the Doha Round paralysis.

And it is that the negotiation of commercial rules outside the auspices of the WTO is a very high risk, because it could ultimately empty this organization of meaning and content; Even so, this same strategy could have positive repercussions, motivating the rest of the international community to move forward in the formulation of rules that continue to facilitate international trade.

The primacy of regulatory harmonization is a prelude to the complexities that countries embarking on future trade negotiations will have to assume increasingly.

The rules and models that are establishing the TPP, CETA etc. will certainly permeate in future agreements.

This is especially important for sectors whose centrality in these types of agreements will increase, such as the regulation of pharmaceutical and biotechnological products.

Trade policy is, now more than ever, part of the policy to promote scientific and technological development. So far the evidence indicates that the culmination of treaties of this nature will be a cornerstone in the advent of a manifest restructuring process of the global trading and investment system.

Marc Solans Solé

E-mail: marcsolans11@gmail.com 